\title{
A INSTITUIÇÃO FISCAL INDEPENDENTE DO BRASIL EM PERSPECTIVA COMPARADA: EM BUSCA DE VIRTUDES E FRAGILIDADES
}

\author{
THE INDEPENDENT FISCAL INSTITUTION OF BRAZIL IN COMPARATIVE PERSPECTIVE: \\ SEARCHING FOR VIRTUES AND FRAILTIES
}

\section{Diogo Luiz Cordeiro Rodrigues}

Mestre em Direito do Estado pela Universidade Federal do Paraná. MSc in Regulation (Financial and Commercial Regulation) pela London School of Economics and Political Science (LSE). Doutorando em Direito Econômico e Financeiro pela Faculdade de Direito da Universidade de São Paulo. Procurador do Estado do Paraná.

E-mail: diogo.luiz.cordeiro@gmail.com

\section{José Mauricio Conti}

Professor de Direito Financeiro da Faculdade de Direito da Universidade de São Paulo. Mestre, Doutor e Livredocente em Direito Financeiro pela Universidade de São Paulo.

E-mail: jmconti@usp.br

Recebido em: 30/06/2020

Aprovado em: 05/11/2020

RESUMO: O presente artigo tem por objetivo central discutir as virtudes e fragilidades da Instituição Fiscal Independente (IFI) do Brasil, agência criada pela Resolução no 42/2016 do Senado Federal para elaborar análises e estimativas acerca de variáveis e cenários fiscais e macroeconômicos, de modo a subsidiar, com análises técnicas e objetivas, as decisões parlamentares no campo das finanças públicas. Do ponto de vista metodológico, o trabalho emprega a abordagem qualitativa de cunho comparativo, situando a IFI do Brasil em relação a experiências estrangeiras e boas práticas internacionais registradas em fontes primárias (legislação) e secundárias (cartilhas internacionais e bibliografia acadêmica). Especial atenção é conferida ao caso do Congressional Budget Office (CBO) dos Estados Unidos. Ademais, em virtude da incipiência da IFI nacional e da própria pesquisa sobre o tema, especialmente no Brasil, este artigo tem caráter marcadamente exploratório. Desse modo, os principais resultados deste trabalho confundem-se com sua sistematização bibliográfica, com a discussão empreendida e com os questionamentos desenvolvidos ao longo do artigo sobre os limites e possibilidades da IFI brasileira. Ao final, conclui-se que a IFI brasileira possui virtudes evidentes, a exemplo da excelência técnica e da destreza gerencial. Nota-se, contudo, que a instituição pode vir a enfrentar dificuldades a longo prazo em razão da fragilidade jurídica de seu estatuto à luz da Constituição e da Lei de Responsabilidade Fiscal.

Palavras-chave: Direito Financeiro. Instituição Fiscal Independente (IFI). Brasil. Conselhos Fiscais. Política Fiscal. Controle Persuasivo. 
ABSTRACT: This article aims to discuss the virtues and frailties of the Independent Fiscal Institution (IFI) of Brazil, an agency created by Resolution No. 42/2016 of the Federal Senate for preparing reports and estimates on fiscal and macroeconomic variables and scenarios, in order to assist parliamentary decisions in the field of public finances with technical and impartial analysis. From a methodological point of view, this work applies a qualitative approach of comparative nature, situating the Brazilian IFI in regard to foreign experience and international best practices as laid out in primary (legislation) and secondary sources (international handbooks and academic studies). Special attention is paid to the case of the United States Congressional Budget Office (CBO). In addition, due to the incipience both of the national IFI and the research on the subject itself, especially in Brazil, this article is markedly exploratory. Thus, the main findings of this work correspond to its bibliographic systematization, discussion and questions on Brazil's IFI limits and possibilities. In the end, this article concludes that the Brazilian IFI carries evident virtues, such as technical excellence and managerial skills of its leaders. It notes, however, that such Institution may face long-term difficulties due to the legal fragility of its status under the Constitution and the Fiscal Responsibility Law.

Keywords: Public Finance Law. Independent Fiscal Institution (IFI). Brazil. Fiscal Councils. Fiscal Policy.

SUMÁRIO: Introdução; 1. Instituição Fiscal Independente: perfil, limites e posibilidades; 1.2. Histórico, motivações e finalidades; 1.3. Competências e instituições rivais; 1.4. Outros aspectos relevantes; 2. Um caso de sucesso: o Congressional Budget Office (CBO) dos Estados Unidos; 2.1. As origens do $\mathrm{CBO} ; 2.2$. Características, competências legais, desafios recorrentes e avaliação do órgão; 3. A situação do Brasil: Conselho de Gestão Fiscal e Instituição Fiscal Independente; 3.1. A IFI brasileira à luz da Resolução no 42/2016 do Senado; 3.2. Atuação da IFI brasileira até o presente momento; 4. Afinal, o que podemos aprender com a experiência estrangeira?; Conclusão; Referências.

\section{INTRODUÇÃO}

Em 2016, de maneira discreta, o Brasil passou a acolher em sua estrutura institucional mais uma agência de controle: a Instituição Fiscal Independente (IFI). Criada pela Resolução $\mathrm{n}^{\circ}$ 42/2016 do Senado Federal, a IFI seria responsável por elaborar análises e estimativas acerca de variáveis e cenários fiscais e macroeconômicos, a fim de subsidiar, com dados técnicos e objetivos, as decisões parlamentares no campo das finanças públicas.

Não se trata de jabuticaba brasileira. Embora praticamente desconhecida em solo nacional, a IFI vem ganhando adeptos mundo afora e, hoje, encontra-se instalada na grande maioria dos países desenvolvidos. Isso porque, em tempos de crise econômica, acredita-se que a IFI seria capaz de auxiliar governos nacionais no controle das contas públicas. No entanto, os méritos dessas instituições para a gestão fiscal ainda são incertos e muito se discute, na literatura internacional, sobre os fatores comportamentais, institucionais e circunstanciais que poderiam auxiliar no sucesso das IFIs em cada país. Nesse contexto, nosso objetivo central neste artigo é discutir as virtudes e fragilidades da IFI brasileira, com base nas boas práticas internacionais e na análise de casos estrangeiros registrados em fontes primárias (legislação) e secundárias (cartilhas internacionais e bibliografia acadêmica). Desse modo, pretendemos apontar possíveis caminhos de reforma, bem como questões de pesquisa relevantes para estudos futuros.

Do ponto de vista metodológico, portanto, a pesquisa formalizada no presente artigo emprega a abordagem qualitativa de cunho comparativo e tem natureza marcadamente exploratória, tendo em conta o estado ainda incipiente da IFI brasileira e da própria pesquisa sobre o tema, especialmente no Brasil. Assim, os principais resultados deste trabalho confundem-se com 
o levantamento bibliográfico, com a discussão empreendida e com os questionamentos desenvolvidos ao longo do artigo sobre os limites e possibilidades da IFI brasileira.

$\mathrm{O}$ artigo encontra-se assim estruturado:

Inicialmente, na seção 2, apresentamos a IFI ao leitor. Nosso intuito, aqui, é esclarecer ao público um conceito que talvez não lhe seja de todo familiar. Afinal, a concepção institucional subjacente à IFI é, de fato, relativamente recente. Assim, com base na literatura técnica já produzida e nas boas práticas recomendadas por organizações internacionais, elucidamos questões conceituais, investigamos o histórico desses órgãos, bem como os motivos de sua existência em diversos países, além de suas competências, finalidades, características e desafios usuais. A seção 3 é dedicada à trajetória do Congressional Budget Office (CBO), a agência autônoma e não partidária responsável por municiar o Congresso americano com informações, análises e estimativas de natureza fiscal ou orçamentária. O CBO é tomado como paradigma, não só em virtude de seu pioneirismo e histórico de sucesso, mas também por conta de paralelos relevantes que podem ser traçados entre a experiência americana e a brasileira, como a modelagem institucional do órgão, o sistema de governo presidencialista e as motivações políticas subjacentes a sua criação.

Em seguida, na seção 4, voltamos nossos olhos para o Brasil, a fim de mapearmos as iniciativas de nosso país rumo ao desenvolvimento de uma IFI, com ênfase no âmbito legalnormativo. Começamos pela Lei de Responsabilidade Fiscal, com seu Conselho de Gestão Fiscal (CGF) e passamos, em seguida, ao relato dos dispositivos constantes da Resolução n 42/2016 e alterações posteriores.

A seção 5, por sua vez, concentra a discussão do artigo. Nela, destacamos as virtudes e fragilidades da IFI brasileira. Indicamos, em síntese, que, até o momento, a IFI nacional tem demonstrado capacidade técnica e liderança suficientes para atuar como ator relevante no debate fiscal interno. No entanto, questionamos se a IFI brasileira, tal como estabelecida no ordenamento jurídico nacional, seria capaz de cumprir os seus propósitos a longo prazo. Afinal, a validade da Resolução no 42/2016 do Senado Federal poderia ser questionada à luz, por exemplo, do princípio da separação de poderes, do regime constitucional aplicável ao controle externo e da Lei de Responsabilidade Fiscal. Além disso, argumentamos que a arquitetura institucional brasileira, repleta de órgãos de controle e instituições de pesquisa atuantes nas áreas econômica, fiscal e orçamentária, poderia suscitar conflitos de competências, além de dúvidas sobre a própria necessidade da instituição.

A última seção, por fim, sintetiza as conclusões do trabalho.

\section{INSTITUIÇÃO FISCAL INDEPENDENTE: PERFIL, LIMITES E POSSIBILIDADES}

Instituição Fiscal Independente (IFI) é um conceito desenvolvido recentemente, em especial no âmbito da Organização para a Cooperação e Desenvolvimento Econômico (OCDE) ${ }^{1}$, com o escopo de caracterizar um conjunto heterogêneo de órgãos, entidades e agências domésticas que exerçam algum papel de controle, geralmente fraco ou persuasivo ${ }^{2}$, sobre a política fiscal $^{3}$ e o

\footnotetext{
${ }^{1}$ Cf. OCDE - Organização para Cooperação e Desenvolvimento Econômico. Recommendation of the Council on Principles for Independent Fiscal Institutions. OECD Network of Parliamentary Budget Officials and Independent Fiscal Institutions, 1-4 p., 2014.

${ }^{2}$ Em geral, a partir de um trocadilho com a palavra "watchdog", que designa agências de controle em países de língua inglesa, a literatura costuma dizer que as IFIs são "cães que ladram, mas não mordem", justamente uma tentativa de ilustrar a fraqueza do controle exercido por essas instituições. Nessa linha, cf. KOPITS, George. Introduction and overview. In: KOPITS, George (Ed.). Restoring public debt sustainability: the role of independent fiscal institutions. Oxford: Oxford University Press, 2013, p. 11.

${ }^{3}$ Política fiscal refere-se à gestão governamental de receitas e despesas com o propósito de influenciar a economia. A política fiscal, juntamente com a política monetária, representa uma das mais importantes ferramentas do governo em

Revista de Direito Brasileira | Florianópolis, SC | v. 27 | n. 10 | p.70-91 | Set./Dez. 2020
} 
processo orçamentário ${ }^{4}$ de seus respectivos países, de modo a lhes conferir maiores graus de transparência, credibilidade e sustentabilidade a médio e longo prazos.

Por vezes, a IFI também é denominada Conselho Fiscal ${ }^{5}$, expressão que, todavia, não parece suficientemente ampla para abarcar todos os modelos hoje praticados mundo afora, ainda que destaque acertadamente a natureza não cogente dessas instâncias ${ }^{6}$.

É que as IFIs podem ser estruturadas sob a forma de Conselhos colegiados, formalmente vinculados ou não a algum Poder do Estado ou órgão autônomo (e.g. Tribunal de Contas), mas também podem receber a roupagem de escritório orçamentário de natureza autônoma, dirigido por apenas um agente público, localizado geralmente na estrutura parlamentar. Desse modo, os formatos possíveis são os mais diversos, conforme as peculiaridades institucionais de cada país ${ }^{7}$. A título meramente ilustrativo, as IFIs dos EUA, Canadá e Austrália seguem o modelo de escritório parlamentar com liderança titularizada por um único sujeito. A IFI belga, por seu turno, liga-se ao Poder Executivo e tem composição colegiada. Portugal também adota o modelo colegiado, mas seu Conselho de Finanças Públicas é autônomo tanto em relação ao Executivo quanto ao Legislativo. Já a França, decerto por pressões corporativas, optou por situar seu Haut Conseil des finances publiques, um órgão colegiado, no âmbito de sua influente Corte de Contas ${ }^{8}$.

Outra nomenclatura recorrente é a de autoridade fiscal independente, mas tal expressão será evitada neste trabalho porque sugere, indevidamente, que as instituições ora examinadas seriam detentores de poder fiscal, prerrogativa reservada para os agentes políticos democraticamente eleitos e, quando muito, a seus subordinados diretos, como os ministros da fazenda e do planejamento. Insista-se: o papel das IFIs restringe-se a monitorar, acompanhar e avaliar a política fiscal, influenciando-a por meio de técnicas persuasivas, de modo a qualificar o debate público e a fim de criar um ambiente negativo para a adoção de medidas fiscais irresponsáveis por parte dos Poderes Executivo e Legislativo, mas sem pretender substituí-los nas atividades de escolha, formulação e implementação das políticas públicas ${ }^{9}$.

sua função estabilizadora, como forma de suavizar os ciclos econômicos e eventuais crises. Sobre o tema, cf. LIMA, Edilberto Carlos Pontes. Curso de Finanças Públicas: Uma Abordagem Contemporânea. São Paulo: Atlas, 2015, p. 28-36.

${ }^{4}$ Processo orçamentário corresponde ao ciclo de preparação, deliberação, aprovação, execução e controle do orçamento público, que congrega receitas e despesas públicas para um determinado período, geralmente de 1 (um) ano. Em sentido amplo, abrange também as peças de planejamento orçamentário de médio e longo prazo, quando existentes. No Brasil, abrange o ciclo da lei orçamentária anual, da lei de diretrizes orçamentárias e do plano plurianual, conforme artigos 165 e seguintes da Constituição de 1988.

${ }^{5}$ A expressão é empregada, sobretudo, em trabalhos mais antigos, bem como aqueles patrocinados pelo Fundo Monetário Internacional (FMI). Cf. EICHENGREEN, Barry; HAUSMANN, Ricardo; VON HAGEN, Jürgen. Reforming budgetary institutions in Latin America: the case for a national fiscal council. In: PICCIOTTO, Robert; WIESNER, Eduardo. Evaluation and development: the institutional dimension. World Bank: World Bank series on evaluation and development, 1998, p. 155-177. Cf. tb. Fundo Monetário Internacional. The Functions and Impact of Fiscal Councils, 2013, p 1-62.

${ }^{6}$ Cf. SILVA, Suzana Tavares da. A Intervenção de Organismos Independentes na Avaliação das Regras Fiscais e o Respectivo Contributo para a Sustentabilidade do Sistema Fiscal - o Conselho das Finanças Públicas. Revista Argumentum - RA, Marília/SP, v. 16, Jan.-Dez. 2015, p. 365.

${ }^{7}$ A diversidade de modelos é encorajada pela OCDE como forma de tornar as IFIs mais eficazes, duradouras e legítimas, tendo em vista as necessidades locais, particularidades institucionais e arcabouços legislativos de cada país. Nessa linha, cf. os princípios 1.1 e 1.2, constantes de OCDE - Organização para Cooperação e Desenvolvimento Econômico. Recommendation of the Council on Principles for Independent Fiscal Institutions. OECD Network of Parliamentary Budget Officials and Independent Fiscal Institutions, 1-4 p., 2014.

${ }^{8}$ As descrições detalhadas de cada uma das IFIs hoje existentes no mundo podem ser colhidas do amplo estudo de VON TRAPP, Lisa; LIENERT, Ian; WEHNER, Joachim. Principles for independent fiscal institutions and case studies. OECD Journal on Budgeting, v. 15, n. 2, 2016, p. 9-272.

${ }^{9}$ No mesmo sentido, entre outros, cf. BIJOS, Paulo. Instituições Fiscais Independentes: Subsídios para a Implantação de um Imperativo Fiscal no País. Senado Federal: Orçamento em Discussão, Brasília/DF, n. 15, 2015, p. 7. No entanto, também há quem advogue a delegação de poder fiscal direto às IFIs. Nessa linha, cf. a discussão travada em DEBRUN, Revista de Direito Brasileira | Florianópolis, SC | v. 27 | n. 10 | p.70-91 | Set./Dez. 2020 


\subsection{HISTÓRICO, MOTIVAÇÕES E FINALIDADES}

Embora o conceito de IFI seja recente, o mesmo não se pode dizer necessariamente do histórico dessas instituições. De fato, ao lado de um número maior de IFIs novatas, como as do Canadá (2008) e do Reino Unido (2010) e da França (2012), também há um conjunto mais restrito de IFIs veteranas, como revelam os exemplos de Bélgica (1936), Países Baixos (1945) e Estados Unidos $(1974)^{10}$.

A nota distintiva mais relevante entre IFIs novatas e veteranas diz respeito ao fator credibilidade: em geral, são as veteranas que ostentam reputação mais sólida e, por conseguinte, detêm maior influência sobre as finanças públicas, além de recursos materiais e humanos mais robustos ${ }^{11}$.

Para alguns, do ponto de vista histórico, a diferença básica entre instituições veteranas e novatas residiria no fato de que estas teriam surgido em resposta aos eventos da crise financeira global de 2008, ao passo que aquelas outras estariam relacionadas a contextos históricos e sociais próprios de seus países ${ }^{12}$. No entanto, essa clivagem não se sustenta. Os efeitos da crise de 2008 parecem estar associados ao surgimento das IFIs europeias novatas, implementadas geralmente por pressões de instâncias comunitárias e agências internacionais de financiamento, com o escopo de dinamizar o controle da dívida e do déficit público ${ }^{13}$, mas não parece explicar, por exemplo, o surgimento das IFIs de Austrália e Coreia do $\mathrm{Sul}^{14}$, bem como o processo de criação da IFI canadense, cujo advento se deve basicamente a um escândalo de corrupção (o sponsorship scandal) e ao fenômeno do superávit surpresa, causado pelo (mau) hábito do então governo Liberal de subestimar a receita projetada para o exercício financeiro, a fim de liberar recursos para uso discricionário ao fim do ano fiscal ${ }^{15}$.

Mesmo no âmbito europeu, pode-se mencionar o exemplo parcialmente destoante do Reino Unido, cujo problema aparentemente mais agudo não estava no monitoramento em si da dívida e do déficit público, algo já feito com qualidade pelo Institute for Fiscal Studies, mas sim nas estimativas elaboradas pelo Tesouro britânico quanto às receitas futuras (fiscal forecasts). Segundo Alan Budd, o Office for Budget Responsibility (OBR) foi proposto pela oposição Conservadora justamente para impedir as estimativas demasiadamente otimistas do Governo Trabalhista, que pareciam acomodar artificialmente a expansão de gastos, em especial no campo da saúde ${ }^{16}$.

De toda sorte, pode-se dizer que a IFI quase sempre é vista como possível antídoto para problemas ou lacunas dos sistemas de controle orçamentário e fiscal, em associação a circunstâncias graves de ordem política ou econômica, que parecem efetivamente precipitar a

Xavier; HAUNER, David; KUMAR, Manmohan S. Independent fiscal agencies. Journal of Economic Surveys, v. 23, n. 1, 2009, p. 44-81.

${ }^{10}$ A clivagem "novatas" versus "veteranas" é utilizada por DEBRUN, Xavier; TAKAHASHI, Keiko. Independent Fiscal Councils in Continental Europe: Old Wine in New Bottles?. DICE Report, v. 9, n. 3, 2011, p. 44-49.

${ }^{11}$ No mesmo sentido, cf. STEWART, Miranda. The Australian Parliamentary Budget Office: A sustainable innovation in fiscal decision-making?. University of Melbourne Legal Studies Research Paper, n. 628, 2013, p. 3/4.

${ }^{12}$ BIJOS, Paulo. Instituições Fiscais Independentes: Subsídios para a Implantação de um Imperativo Fiscal no País. Senado Federal: Orçamento em Discussão, Brasília/DF, n. 15, 2015, p. 8.

${ }^{13}$ SILVA, Suzana Tavares da. A Intervenção de Organismos Independentes na Avaliação das Regras Fiscais e o Respectivo Contributo para a Sustentabilidade do Sistema Fiscal - o Conselho das Finanças Públicas. Revista Argumentum - RA, Marília/SP, v. 16, Jan.-Dez. 2015, p. 360.

${ }^{14}$ A observação é de KOPITS, George. Introduction and overview. In: KOPITS, George (Ed.). Restoring public debt sustainability: the role of independent fiscal institutions. Oxford: Oxford University Press, 2013, p. 3

${ }^{15}$ RODRIGUES, Diogo Luiz Cordeiro. Orçamento Público no Canadá: a emergência da Instituição Fiscal Independente. Rio de Janeiro: Lumen Juris, 2016.

${ }^{16}$ BUDD, Alan. Preface. In: KOPITS, George (Ed.). Restoring public debt sustainability: the role of independent fiscal institutions. Oxford: Oxford University Press, 2013, p. xvi.

Revista de Direito Brasileira | Florianópolis, SC | v. 27 | n. 10 | p.70-91 | Set./Dez. 2020 
reforma institucional. De fato, sem uma conjuntura crítica ${ }^{17}$, é bastante provável que os governos continuem simplesmente a acomodar interesses diversos, postergando medidas de ajuste mais severas, geralmente impopulares do ponto de vista eleitoral. Com a implantação da IFI, busca-se justamente bloquear a reiteração dessa tendência, conferindo-se uma dose maior de profissionalismo às políticas fiscal e orçamentária, de modo a despi-las dos excessos da política partidária, centrada em benefícios de curto prazo para os atores diretamente envolvidos ${ }^{18}$.

Um paralelo possível seria a política monetária ${ }^{19}$, área das finanças públicas costumeiramente delegada a bancos centrais técnicos e fortes. A comparação, no entanto, é imperfeita: ao contrário da política monetária, cujos objetivos são mais claros e universais, a política fiscal constitui tarefa substancialmente mais polêmica, não havendo consensos numéricos acerca de suas metas principais, tal como a busca de uma adequada relação dívida/PIB ${ }^{20}$. Bem por isso, costuma-se advogar um papel mais brando para a IFIs, sem qualquer pretensão de que a política fiscal em si seja delegada a essas instâncias, o que, aliás, conforme já sugerido, seria profundamente antidemocrático ${ }^{21}$.

\subsection{COMPETÊNCIAS E INSTITUIÇÕES RIVAIS}

Em seu catálogo de princípios, todos elaborados a partir de experiências concretas dos próprios países, a OCDE estabelece algumas prescrições específicas a respeito das competências a serem atribuídas às IFIs, enfatizando aspectos formais, substantivos e inter-institucionais.

Sob o prisma formal, o Principio 3.1 prescreve que as competências sejam asseguradas claramente em legislação superior (higher level legislation) e o Princípio 3.3 recomenda que a atuação da IFI esteja integrada ao processo orçamentário. Além disso, já sob o prisma substantivo, este último Princípio apresenta um rol exemplificativo de tarefas que podem atribuídas às IFIs, quais sejam, (i) projeções econômicas e fiscais de curto e médio prazos, além de cenários de longo prazo; (ii) projeções de base (considerando-se políticas inalteradas); (iii) análise da proposta orçamentária do Poder Executivo; (iv) monitoramento de aderência do governo a regras fiscais ou metas oficiais; (v) análise de custos de propostas legislativas significativas e (vi) estudos analíticos sobre temas selecionados ${ }^{22}$.

Naturalmente, do ponto de vista mais concreto, as competências da IFI variam de país a país, conforme as finalidades que se queira atingir e a depender também, claro, de circunstâncias locais de caráter político, econômico ou social ${ }^{23}$. Vale registrar que algumas IFIs exercem outras tarefas que não aquelas exemplificadas acima. A própria OCDE aponta alguns exemplos: o Bureau

17 Sobre o conceito de "conjunta crítica", cf. PRADO, Mariana; TREBILCOCK, Michael. Path dependence, development, and the dynamics of institutional reform. University of Toronto Law Journal, v. 59, n. 3, 2009, p. 355358.

${ }^{18}$ BUDD, Alan. Preface. In: KOPITS, George (Ed.). Restoring public debt sustainability: the role of independent fiscal institutions. Oxford: Oxford University Press, 2013, p. xiv.

${ }^{19}$ Política monetária diz respeito ao controle da oferta de moeda na economia e envolve a calibragem direta ou indireta da taxa de juros pelos bancos centrais. Sobre o assunto, cf. LIMA, Edilberto Carlos Pontes. Curso de Finanças Públicas: Uma Abordagem Contemporânea. São Paulo: Atlas, 2015, p. 32-35.

${ }^{20} \mathrm{O}$ ponto é salientado por BUDD, Alan. Preface. In: KOPITS, George (Ed.). Restoring public debt sustainability: the role of independent fiscal institutions. Oxford: Oxford University Press, 2013, p. xiv/xv e DEBRUN, Xavier; TAKAHASHI, Keiko. Independent Fiscal Councils in Continental Europe: Old Wine in New Bottles?. DICE Report, v. 9, n. 3, 2011, p. 45.

${ }^{21}$ Em sentido aproximado, cf. SILVA, Suzana Tavares da. A Intervenção de Organismos Independentes na Avaliação das Regras Fiscais e o Respectivo Contributo para a Sustentabilidade do Sistema Fiscal - o Conselho das Finanças Públicas. Revista Argumentum - RA, Marília/SP, v. 16, Jan.-Dez. 2015, p. 366.

${ }^{22}$ Cf. OCDE - Organização para Cooperação e Desenvolvimento Econômico. Recommendation of the Council on Principles for Independent Fiscal Institutions. OECD Network of Parliamentary Budget Officials and Independent Fiscal Institutions, 1-4 p., 2014.

${ }^{23}$ Mais do que constatação, a necessidade de que IFI ajuste-se ao ambiente local é uma prescrição da OCDE, conforme seus princípios 1.1 e 1.2, já mencionados de passagem (v. nota 7).

Revista de Direito Brasileira | Florianópolis, SC | v. 27 | n. 10 | p.70-91 | Set./Dez. 2020 
for Economic Policy Analysis da Holanda elabora estudos sobre os custos de plataformas eleitorais e a IFI da Coréia do Sul, conhecida como Korean National Assembly Budget Office encarrega-se de avaliar o desempenho de programas ${ }^{24}$.

Pode-se dizer que a questão referente às competências talvez seja a mais polêmica sob o prisma jurídico, pois invariavelmente as tarefas a serem atribuídas à IFI já são exercidas de algum modo por outras agências, como institutos de pesquisas e tribunais de contas, ou pelo menos se encontram no campo natural de atuação dessas instâncias pré-existentes, conforme previsões constitucionais ou estatutárias. Aliás, é justamente a existência de prévios arranjos destinados ao controle das finanças públicas em tais países que torna mais premente a seguinte questão: as IFIs são mesmo necessárias?

Aqui, deve-se ressaltar que as IFIs não têm a pretensão de ineditismo quanto às tarefas propriamente ditas, mas sim em relação ao modo de exercê-las. Com as IFIs, busca-se um novo olhar sobre velhos problemas. Ou, pelo menos, uma abordagem mais isenta e transparente acerca de questões já tratadas por órgãos viciados, seja por razões político-eleitorais, seja por razões ideológicas, institucionais ou mesmo corporativas.

Nesse contexto, é costumeiro encontrar na literatura alusões ao fato de que IFIs adotam uma postura prospectiva (forward-looking), em contraste com a abordagem retrospectiva dos órgãos de auditoria tradicionais, que só verificam falhas quando estas já foram perpetuadas ${ }^{25}$. É o que parece ocorrer na Coréia do Sul, por exemplo, já que no país asiático as avaliações de programas são repartidas entre a IFI e o órgão de auditoria, cada qual com uma missão específica: enquanto este último concentra-se nas auditorias financeiras, aquele outro encarrega-se das análises de desempenho quanto à eficiência, eficácia e efetividade dos programas ${ }^{26}$.

Mas há também casos em que a mesma atividade é efetivamente realizada por dois órgãos, de maneira concorrente, de modo que o trabalho da IFI represente um verdadeiro check em relação à outra instância, geralmente uma agência do governo. É o que ocorre nos Estados Unidos quanto às projeções econômicas e fiscais, realizadas tanto pelo Executivo quanto pelo Congressional Budget Office (CBO), a IFI daquele país ${ }^{27}$. E há também casos em que um órgão efetivamente deixa de exercer determinada tarefa em prol da IFI. O Reino Unido é um exemplo. Segundo Kopits, a introdução do novo OBR também teve por objetivo melhorar a fiscalização do cumprimento das metas fiscais, tarefa que não vinha sendo exercida a contento pelo National Audit Office, o órgão de auditoria britânico ${ }^{28}$.

Naturalmente, como se pode imaginar a partir dos exemplos indicados, a chegada de uma nova e badalada instituição como a IFI nem sempre é acolhida sem resistências por parte de agências já estabelecidas. O que é compreensível, até porque, como registra Usman Chohan, a arena política é inerentemente uma equação de soma zero, de modo que qualquer espaço preenchido pela IFI representa uma perda de espaço, em igual medida, por outro parte de outro ator

\footnotetext{
${ }^{24}$ Cf. OCDE - Organização para Cooperação e Desenvolvimento Econômico. Recommendation of the Council on Principles for Independent Fiscal Institutions. OECD Network of Parliamentary Budget Officials and Independent Fiscal Institutions, 2014, p. 3.

${ }^{25}$ Entre outros, cf. KOPITS, George. Introduction and overview. In: KOPITS, George (Ed.). Restoring public debt sustainability: the role of independent fiscal institutions. Oxford: Oxford University Press, 2013, p. 2. Vale ressaltar, no entanto, que esse rotineiro apontamento parece ignorar o fato de que os Tribunais de Contas e órgãos de auditoria têm ampliado cada vez mais seu escopo de atuação, conferindo-lhe uma ampla dimensão prospectiva, como no caso das auditorias de desempenho. Acertada, portanto, a opinião de BIJOS, Paulo. Instituições Fiscais Independentes: Subsídios para a Implantação de um Imperativo Fiscal no País. Senado Federal: Orçamento em Discussão, Brasília/DF, n. 15, 2015, p. 11.

${ }^{26}$ BIJOS, Paulo. Instituições Fiscais Independentes: Subsídios para a Implantação de um Imperativo Fiscal no País. Senado Federal: Orçamento em Discussão, Brasília/DF, n. 15, 2015, p. 12.

${ }^{27}$ JOYCE, Philip. The Congressional Budget Office: honest numbers, power, and policymaking. Washington D.C.: Georgetown University Press, 2011, p. 5.

${ }^{28}$ KOPITS, George. Introduction and overview. In: KOPITS, George (Ed.). Restoring public debt sustainability: the role of independent fiscal institutions. Oxford: Oxford University Press, 2013, p. 2.
}

Revista de Direito Brasileira | Florianópolis, SC | v. 27 | n. 10 | p.70-91 | Set./Dez. 2020 
político previamente existente ${ }^{29}$. Não por outro motivo, os Tribunais de Contas de Espanha, Itália e França impuseram obstáculos à implantação da IFI, a ponto de, no último país, a IFI ser situada na própria Cour des Comptes como solução ao impasse institucional, como já apontado ${ }^{30}$. E também não é raro, claro, que as próprias instâncias democráticas resistam às IFIs. Na Hungria, a IFI foi desarticulada pelo governo após dois anos de funcionamento, em resposta a relatórios críticos por parte do órgão ${ }^{31}$. Já no Canadá, a retaliação governista foi manifestada por meio de restrições orçamentárias e negativa de acesso a documentos essenciais para o desempenho das funções do Parliamentary Budget Officer (PBO) ${ }^{32}$.

Desse modo, resta claro que o adequado funcionamento da IFI pressupõe necessariamente a obtenção de consensos políticos sólidos e abrangentes. Do contrário, a introdução de uma IFI pode causar efeito oposto ao desejado, incentivando hostilidades entre órgãos, confusões de procedimentos ou mera indiferença a suas análises.

\subsection{OUTROS ASPECTOS RELEVANTES}

O catálogo de princípios de OCDE contempla outros aspectos críticos para o sucesso das IFIs. Além do encorajamento à diversidade de modelos, consoante as particularidades institucionais e arcabouços legislativos de cada país ${ }^{33}$, a OCDE prescreve às IFIs as seguintes características: independência e não partidarismo (princípios 2.1 a 2.6); autonomia financeira compatível com a de outros órgãos independentes (princípio 4.1); mecanismos claros de interação com o Poder Legislativo (princípios 5.1 e 5.2); garantia de acesso a informações e dados detidos por órgãos administrativos (princípios 6.1 e 6.2); transparência e tempestividade na operação da IFI (princípios 7.1 a 7.4); comunicação efetiva com imprensa, sociedade civil e interessados (princípio 8.1) e, por fim, avaliação externa do trabalho efetuado pela IFI (princípio 9.1) ${ }^{34}$.

\section{UM CASO DE SUCESSO: O CONGRESSIONAL BUDGET OFFICE (CBO) DOS ESTADOS UNIDOS}

O Congressional Budget Office (CBO) é uma agência autônoma não partidária vinculada ao Congresso americano. Criado pelo Congressional Budget and Impoundment Control Act de 1974, o CBO iniciou suas operações em 1975, sendo responsável, a partir de então, por fornecer análises de políticas públicas e estudos de impacto orçamentário imparciais e de alta qualidade a ambas as Casas do Congresso, principalmente por meio de suas comissões permanentes devotadas às finanças públicas, como as Comissões de Orçamento e de Apropriações ${ }^{35}$.

\footnotetext{
${ }^{29}$ CHOHAN, Osman W. Canada and the global network of parliamentary budget officers. Canadian parliamentary review, v. 36, n. 3, 2013, p. 17.

${ }^{30}$ A costumeira resistência dos Tribunais de Contas é salientada por KOPITS, George. Introduction and overview. In: KOPITS, George (Ed.). Restoring public debt sustainability: the role of independent fiscal institutions. Oxford: Oxford University Press, 2013, p. 10.

${ }^{31}$ KOPITS, George; ROMHÁNYI, Balázs. Hungary: A Short-Lived Fiscal Watchdog. In: KOPITS, George (Ed.). Restoring public debt sustainability: the role of independent fiscal institutions. Oxford: Oxford University Press, 2013, p. 212-233.

${ }^{32}$ Cf. RODRIGUES, Diogo Luiz Cordeiro. Orçamento Público no Canadá: a emergência da Instituição Fiscal Independente. Rio de Janeiro: Lumen Juris, 2016, p. 155-195.

${ }^{33} \mathrm{~V}$. nota 7.

${ }^{34}$ Cf. OCDE - Organização para Cooperação e Desenvolvimento Econômico, op. cit., p. 2-4.

${ }^{35}$ A referência mais importante sobre o CBO na atualidade é o já citado JOYCE, Philip. The Congressional Budget Office: honest numbers, power, and policymaking. Washington D.C.: Georgetown University Press, 2011. Recentemente, o autor publicou uma versão resumida de sua obra. Cf. JOYCE, Philip. The Congressional Budget Office at Middle Age. Hutchins Center Working Papers, 9. 1 -30, 2015. Outras fontes importantes são as seguintes: RIVLIN, Alice. Politics and Independent Analysis e STEUERLE, Eugene and RENNANE, Stephanie. United States: Pioneer in Fiscal Surveillance, ambos presentes em KOPITS, George (Ed.). Restoring public debt sustainability: the Revista de Direito Brasileira | Florianópolis, SC | v. 27 | n. 10 | p.70-91 | Set./Dez. 2020
} 
Das centenas de IFIs hoje existentes ao redor do mundo, o CBO representa uma escolha natural para fins comparativos, tendo em vista seu pioneirismo e, especialmente, seu histórico de sucesso. Pode-se dizer que diversas práticas adotadas pelo $\mathrm{CBO}$ ao longo de sua trajetória viriam a se tornar verdadeiros paradigmas de conduta para IFIs novatas. Basta notar que a agência congressual norte-americano serviu de inspiração direta para muitos órgãos congêneres criados recentemente, como revelam os exemplos de Canadá, Coreia do Sul e México ${ }^{36}$.

Para o Brasil, a análise do caso americano revela-se especialmente importante, dadas as similitudes institucionais entre os dois países, bem como suas escolhas em relação à IFI. Afinal, em ambos os casos, trata-se de IFIs modeladas como escritórios parlamentares autônomos atuantes em sistemas presidencialistas com separação de poderes entre Executivo e Legislativo.

Feitas essas breves ponderações, analisemos mais de perto o caso norte-americano.

\subsection{AS ORIGENS DO CBO}

O CBO nasceu como subproduto de um movimento mais amplo de retomada do poder da bolsa ${ }^{37}$ por parte do Congresso americano, que se viu ofuscado pelo Poder Executivo na seara orçamentária durante décadas, a começar pela edição, em 1921, do Budget and Accounting Act. Esse estatuto não só atribuiu formalmente ao Presidente da República a prerrogativa de apresentar uma proposta de orçamento anual às Casas Legislativas, como também criou o Bureau of Budget, hoje conhecido como Office of Management and Budget (OMB), "um dos maiores centros de poder no sistema político norte-americano", nas palavras de Eduardo Mendonça ${ }^{38}$. O OMB é a instância administrativa responsável por auxiliar o Presidente na elaboração do orçamento, na negociação com outros departamentos, na análise de opções alternativas e na defesa das posições oficiais do governo, competindo-lhe, ademais, gerenciar a execução e o controle da execução orçamentária no nível departamental ${ }^{39}$.

Durante anos, a supremacia presidencial não causou maiores constrangimentos no cenário político-parlamentar. Inicialmente, porque o intuito básico do Budget and Accounting Act era justamente impedir a escalada dos gastos públicos. Em seguida, com a crise de 1929, o crescimento do Executivo passou a ser legitimado pela necessidade de estímulo à economia, com base nos pressupostos da teoria keynesiana, fomentada por Franklin Roosevelt. E quando se esperava uma normalização no estado de coisas, eclodiu a Segunda Guerra Mundial, que gerou nova demanda por gastos e centralização administrativa no Poder Executivo. Na sequência, os riscos inerentes à Guerra Fria e a geração de novas receitas parecem ter pavimentado o caminho para a expansão do déficit público e para consolidação da primazia orçamentária e financeira do Presidente, agora planejador em chefe $e^{40}$.

role of independent fiscal institutions. Oxford: Oxford University Press, 2013. Por fim, outra importante fonte de informações é o detalhado estudo de VON TRAPP, Lisa; LIENERT, Ian; WEHNER, Joachim. Principles for independent fiscal institutions and case studies. OECD Journal on Budgeting, v. 15, n. 2, 2016, p. 257-272.

${ }^{36} \mathrm{Cf}$. VON TRAPP, Lisa; LIENERT, Ian; WEHNER, Joachim. Principles for independent fiscal institutions and case studies. OECD Journal on Budgeting, v. 15, n. 2, 2016, p. 88, 154 e 166.

${ }^{37}$ Poder da bolsa (ou power of the purse, no original) é a expressão que se usa geralmente para sintetizar o controle do Parlamento sobre as finanças públicas, posição garantida formalmente pela maioria esmagadora das Constituições democráticas ao redor do mundo. Nos EUA, a ideia está consagrada na seção $8^{\mathrm{a}}$ do art. $1^{\mathrm{o}}$ da Constituição. Sobre o tema do "poder da bolsa" e seus limites contemporâneos, cf. WEHNER, Joachim. Assessing the power of the purse: An index of legislative budget institutions. Political studies, v. 54, n. 4, p. 767-785, 2006.

${ }^{38}$ MENDONÇA, Eduardo Furtado Bastos de. A constitucionalização das finanças públicas no Brasil: devido processo orçamentário e democracia. Rio de Janeiro: Renovar, 2010, p. 357.

${ }^{39}$ STEUERLE, Eugene and RENNANE, Stephanie. United States: Pioneer in Fiscal Surveillance. In: KOPITS, George (Ed.). Restoring public debt sustainability: the role of independent fiscal institutions. Oxford: Oxford University Press, 2013, p. 101.

${ }^{40}$ Sobre a história do orçamento americano, v. MENDONÇA, Eduardo Furtado Bastos de. A constitucionalização das finanças públicas no Brasil: devido processo orçamentário e democracia. Rio de Janeiro: Renovar, 2010, p. 353/381.

Revista de Direito Brasileira | Florianópolis, SC | v. 27 | n. 10 | p.70-91 | Set./Dez. 2020 
Por volta dessa época, segundo Joyce e Reischauer, o Congresso atuava de maneira errática e casuística no processo orçamentário, sem possuir uma visão global do orçamento e dos fundamentos fiscais do Estado, o que o impedia de contribuir para o aperfeiçoamento das políticas públicas. Encontrava-se, portanto, em flagrante desvantagem diante do Poder Executivo ${ }^{41}$.

No entanto, ao final dos 60, o modelo keynesiano começou a dar claros sinais de fadiga. A situação agravou-se com eclosão da Guerra do Vietnã. Na mensagem do orçamento de 1967, o Presidente Lindon Johnson solicitou autorização de gastos para o esforço de guerra e, também, para o chamado Great Society, um amplo programa social do governo. Johnson afirmava que ambas as ações poderiam ser financiadas simultaneamente com as receitas já previstas. No entanto, apenas um ano depois, o Presidente solicitaria aumento da carga tributária para financiar os dois projetos $^{42}$.

Com a eleição do Republicano Richard Nixon, a guerra do orçamento ganharia novos contornos. Diante de um Congresso dominado pelos Democratas, Nixon deu início a uma agenda voltada à contenção de gastos e os conflitos entre os Poderes intensificaram-se. O Presidente reivindicava um amplo poder discricionário de contingenciamento (impoundment), recusando-se a desembolsar recursos apropriados pelo Congresso em prol de vários programas sociais. Uma espécie de veto parcial de facto sobre o orçamento, prerrogativa inexistente na Constituição americana. Ademais, o Republicano forçava o Congresso a estipular tetos de gastos, mas o Poder Legislativo não parecia ter meios de fazê-lo por conta própria. $\mathrm{O}$ que se verificou, então, foi a completa fragilidade do Congresso para controlar o orçamento e impedir as investidas do Presidente $^{43}$. Essa constatação, somada à cada vez mais pronunciada fragilidade de Nixon em virtude do escândalo Watergate ${ }^{44}$, gerou a janela de oportunidade necessária para o Congresso, enfim, retomar seu protagonismo na esfera orçamentária. E isso viria a ocorrer efetivamente com a edição do Congressional Budget and Impoundment Control Act (ou Budget Act), de 1974 ${ }^{45}$.

O Budget Act de 1974 não só regulamentou o contingenciamento orçamentário ${ }^{46}$ como também estabeleceu importantes medidas organizacionais para conferir ao Congresso uma visão global acerca do orçamento público. Foram criadas Comissões de Orçamento na Câmara dos Representantes e no Senado, encarregadas de elaborar anualmente a chamada "resolução orçamentária", ato conjunto que regulamenta o processo orçamentário parlamentar. Em síntese, a resolução simplifica a proposta orçamentária presidencial, de modo a expressar um modelo de política fiscal claro e coerente. Ademais, a resolução contém uma estimativa de receitas e limites não vinculantes de gastos, conforme categorias funcionais (e.g. transporte, saúde, energia), além de procedimentos internos para guiar os trabalhos de outras Comissões congressuais de ali em diante $^{47}$.

\footnotetext{
${ }^{41}$ JOYCE, Philip G.; REISCHAUER, Robert D. Deficit Budgeting: The Federal Budget Process and Budget Reform. Harvard Journal on Legislation, v. 29, , 1992, p. 431.

42 JOYCE, Philip. The Congressional Budget Office: honest numbers, power, and policymaking. Washington D.C.: Georgetown University Press, 2011, p. 15.

${ }^{43}$ JOYCE, Philip. The Congressional Budget Office: honest numbers, power, and policymaking. Washington D.C.: Georgetown University Press, 2011, p. 16.

${ }^{44}$ A menção ao "Watergate" é de STEUERLE, Eugene and RENNANE, Stephanie. United States: Pioneer in Fiscal Surveillance. In: KOPITS, George (Ed.). Restoring public debt sustainability: the role of independent fiscal institutions. Oxford: Oxford University Press, 2013, p. 99.

${ }^{45}$ ESTADOS UNIDOS. CONGRESSO. U. S. Congressional Budget and Impoundment Control Act of 1974. Public Law, n. 93-344, July 12, 1974. Texto atualizado disponível em <https://www.govinfo.gov/content/pkg/COMPS10356/pdf/COMPS-10356.pdf> (acesso em 24/10/2020)

${ }^{46}$ Os contingenciamentos podem ser classificados como "rescissions" (cancelamentos) ou "deferrals" (retardamentos), nos termos da Seção 1011 (1) e (3) do Budget Act.

${ }^{47}$ O papel da "budget resolution" é explicado em detalhes por DAUSTER, William. The Congressional Budget Process. In: GARRETT, Elizabeth; GRADDY, Elizabeth and JACKSON, Howell. Fiscal Challenges: an interdisciplinary approach to budget policy. Cambridge: Cambridge University Press, 2008, p. 4-35.
}

Revista de Direito Brasileira | Florianópolis, SC | v. 27 | n. 10 | p.70-91 | Set./Dez. 2020 
E, mais importante, o Budget Act previu a criação do CBO, a fim de que o Congresso não mais dependesse das informações enviesadas do Poder Executivo para tomar suas decisões orçamentárias e econômicas.

\subsection{CARACTERÍSTICAS, COMPETENCIAS LEGAIS, DESAFIOS RECORRENTES E AVALIAÇÃO DO ÓRGÃO}

Evidentemente, o CBO não teria alcançado o atual sucesso sem garantias legais que lhe permitissem exercer plenamente o seu potencial. Daí a importância de seu estatuto jurídico.

O Budget Act garantiu amplo apoio político ao Diretor do CBO, que é nomeado pelos Presidentes da Câmara dos Representantes e do Senado a partir de indicações feitas pelas Comissões de Orçamento de cada Casa Legislativa. Além disso, ao Diretor do CBO é conferido mandato fixo de 4 (quatro) anos, o que, em tese, contribui para a ampliação de sua autonomia pessoal. De todo modo, o Budget Act resguarda o profissionalismo na condução do CBO ao exigir que a nomeação de seu líder se dê "sem qualquer consideração por filiação partidária e somente com base em sua aptidão para desempenhar seus deveres"48. Na prática, indica-se geralmente alguém identificado com a agremiação política no poder, mas Steuerle e Rennane comentam que todos os Diretores do CBO, até aqui, teriam levado a sério a missão de conduzir a agência com imparcialidade e absoluto profissionalismo ${ }^{49}$.

Além disso, o Diretor também é autorizado por lei a, eventualmente, contratar especialistas, consultores ou organizações para trabalhos específicos ou temporários, que não demandem mais de um ano para sua realização ${ }^{50}$. Atualmente, o CBO conta com aproximadamente 235 funcionários ${ }^{51}$.

O Budget Act também detalha as relações interinstitucionais do CBO e estabelece amplas prerrogativas em prol da agência parlamentar. Em sua relação com o Executivo, o Diretor do CBO é legalmente autorizado a "assegurar informações, dados, estimativas e estatísticas diretamente dos diversos departamentos, agências e estabelecimentos do Poder Executivo e de agências reguladoras e comissões do Governo". No mesmo dispositivo, o Budget Act também autoriza as instâncias do Poder Executivo a prover todas as informações que o Diretor do CBO considerar necessárias para sua missão, exceto aquelas cuja publicação poderia acarretar violação de lei. Enfim, mediante entendimentos com o chefe de cada repartição do Executivo, o Diretor do CBO também é autorizado a utilizar seus serviços, facilidades e pessoal, com ou sem reembolso [Budget Act, Sec. 201 (d)]. Quanto às relações do CBO com outras agências do Congresso, o Budget Act prevê prerrogativas semelhantes, autorizando-o a coletar informações, dados, estimativas e estatísticas do Government Accountability Office (GAO) e da Biblioteca do Congresso, além de usar seus serviços, facilidades e pessoal, mediante entendimentos, tudo com o "propósito de coordenar as operações do Escritório com aquelas de outras agências congressuais, a fim de utilizar da maneira mais efetiva as informações, serviços e capacidades de todas elas no desempenho de suas respectivas responsabilidades" 52 .

\footnotetext{
${ }^{48}$ ESTADOS UNIDOS. CONGRESSO. U. S. Congressional Budget and Impoundment Control Act of 1974. Sec. 201 (1) (2). Public Law, n. 93-344, July 12, 1974.

${ }^{49}$ STEUERLE, Eugene and RENNANE, Stephanie, "United States: Pioneer in Fiscal Surveillance", In: KOPITS, George (Ed.). Restoring public debt sustainability: the role of independent fiscal institutions. Oxford: Oxford University Press, 2013, p. 104.

${ }^{50}$ ESTADOS UNIDOS. CONGRESSO. U. S. Congressional Budget and Impoundment Control Act of 1974. Sec. 201 (5) (c). Public Law, n. 93-344, July 12, 1974.

51 ESTADOS UNIDOS. Congressional Budget Office. Organization and Staffing [website]. Disponível em <https://www.cbo.gov/about/organization-and-staffing> (acesso em 24/10/2020)

${ }^{52}$ ESTADOS UNIDOS. CONGRESSO. U. S. Congressional Budget and Impoundment Control Act of 1974. Sec. 201 (e). Public Law, n. 93-344, July 12, 1974.
}

Revista de Direito Brasileira | Florianópolis, SC | v. 27 | n. 10 | p.70-91 | Set./Dez. 2020 
Na prática, segundo Von Trapp, Lienert e Wehner, "o estafe técnico do CBO e do OMB trocam informações regularmente, incluindo as premissas subjacentes a suas perspectivas sobre cenários econômicos e orçamentários". Quanto ao GAO, o braço investigativo do Congresso, os autores apontam que as agências "possuem uma relação particularmente próxima", a fimm de "assegurar complementaridade no suporte ao Congresso, especialmente no que diz respeito ao trabalho de estimar custos de novas políticas públicas" 53 .

Já com relação aos parlamentares e Comissões por eles integradas, vale pontuar que o CBO não se comporta como se órgão de assessoria fosse. Na verdade, cada Comissão possui seu próprio estafe, composto de servidores nomeados por critérios políticos. Já o CBO, além de atuar de maneira técnica e isenta, possui considerável discricionariedade para formatar sua própria agenda em matérias não estipuladas em lei, fazendo-o de maneira bastante proativa desde os seus primeiros anos, quando dirigido pela economista Alice Rivlin ${ }^{54}$. De todo modo, dadas as limitações de pessoal e tendo em vista os termos do Budget Act, Sec. 202 (a) ${ }^{55}$, o CBO prioriza as demandas das Comissões, especialmente as de Orçamento ${ }^{56}$.

De acordo com o Budget Act, além das atividades rotineiras de apoio às Comissões, o CBO deve apresentar somente um relatório obrigatório no ano, por volta do dia 15 de fevereiro, que deverá conter basicamente uma discussão sobre as prioridades orçamentárias nacionais e meios alternativos de alocação de recursos entre os principais programas ou categorias funcionais ${ }^{57}$.

Atualmente, além da análise de políticas públicas, feita de maneira tão imparcial quanto possível, o CBO apresenta uma série de outros produtos ${ }^{58}$. Nada obstante, a agência confere especial atenção às estimativas de impacto orçamentário de propostas legislativas e programas governamentais de caráter contínuo, tarefa que mais influência lhe confere nos dias de hoje ${ }^{59}$.

Curiosamente, trata-se de tarefa surgida apenas em momento posterior da história fiscal americana, quando promulgado o Budget Enforcement Act (BEA), de 1990. Embora o BEA ainda se preocupe com metas para despesas discricionárias, variáveis anualmente, seu maior cuidado é com as despesas fixas ou obrigatórias, rigidamente estabelecidas em leis materiais permanentes. São elas que mais pressionam o déficit público e o estoque da dívida. Para superar o problema do controle referente às despesas obrigatórias, o BEA criou o chamado sistema pay-as-you-go (ou PAYGO), segundo o qual toda expansão de gasto obrigatório ou concessão de incentivo fiscal deve ser neutralizada mediante aumento permanente da receita (elevação da carga tributária) ou redução permanente da despesa (corte de gastos) ${ }^{60}$.

$\mathrm{O}$ CBO tornou-se imprescindível na engrenagem de funcionamento do scoring process previsto no BEA e leis similares supervenientes, uma vez que é dele o papel de dar a palavra final técnica, no âmbito do Congresso, acerca do impacto de novos programas a médio e longo prazo, opinando pela viabilidade ou não das propostas de neutralização indicadas pelos autores do projetos. Nesse contexto, aponta-se que o CBO foi fundamental para o fracasso de reforma da saúde tentada por Bill Clinton em 1994, mas também para o êxito de iniciativa congênere

\footnotetext{
${ }^{53}$ VON TRAPP, Lisa; LIENERT, Ian; WEHNER, Joachim, op. cit., v. 15, n. 2, 2016, p. 260.

${ }^{54}$ Ibidem, p. 259.

${ }^{55}$ ESTADOS UNIDOS. CONGRESSO. U. S. Congressional Budget and Impoundment Control Act of 1974. Sec. 202 (a). Public Law, n. 93-344, July 12, 1974.

${ }^{56}$ No mesmo sentido, cf. STEUERLE, Eugene and RENNANE, Stephanie, op. cit., p. 102.

${ }^{57}$ ESTADOS UNIDOS. CONGRESSO. U. S. Congressional Budget and Impoundment Control Act of 1974. Sec. 202 (e)(1). Public Law, n. 93-344, July 12, 1974.

${ }^{58}$ Conferir a extensa listagem em <https://www.cbo.gov/about/products >

${ }^{59}$ No mesmo sentido, cf. RIVLIN, Alice, "Politics and Independent Analysis", In: KOPITS, George (Ed.). Restoring public debt sustainability: the role of independent fiscal institutions. Oxford, Oxford University Press, 2013 , p. 24.

${ }^{60}$ No Brasil, a Lei de Responsabilidade Fiscal adotou uma versão "tropicalizada" do PAYGO em seus artigos 14 e 17. O funcionamento do processo "PAYGO", suas origens nos EUA e sua adaptação ao ordenamento brasileiro são tratados em detalhes em OLIVEIRA, Weder de, Curso de Responsabilidade Fiscal, $2^{\mathrm{a}}$ ed. Belo Horizonte: Fórum, 2015, p. 833-1016.
}

Revista de Direito Brasileira | Florianópolis, SC | v. 27 | n. 10 | p.70-91 | Set./Dez. 2020 
patrocinada por Barack Obama em 2010 (o famoso Affordable Care Act ou Obamacare) ${ }^{61}$. Possteriormente, o CBO foi apontado pela imprensa americana como ator-chave no desenrolar do processo congressual de aprovação da proposta de Donald Trump para a saúde, que deve substituir o Obamacare ${ }^{62}$.

Em geral, pode-se dizer que o saldo institucional do CBO é, até aqui, amplamente positivo. $\mathrm{O}$ CBO integrou-se muito bem ao processo orçamentário americano e, hoje, representa uma peça fundamental para o bom funcionamento do Congresso, que passou a contar com uma fonte mais do que confiável de informação técnica para tomar as decisões de sua alçada, independentemente do partido que se encontre no poder.

Ademais, o fato é que as análises e estimativas do CBO são frequentemente citadas ou debatidas na grande mídia, inclusive por importantes formadores de opinião na área econômica ${ }^{63}$. Mais do que mera assessoria parlamentar com autonomia técnica, o CBO tornou-se um verdadeiro e respeitado player no mundo das finanças públicas, com direito a voz e atenção de todos os interessados nesse campo. Aponta-se que grande parte desse êxito deve-se ao gênio dos primeiros Diretores, especialmente Alice Rivlin, que fomentaram no CBO uma cultura de imparcialidade, proatividade, engajamento e comunicação direta com a sociedade civil ${ }^{64}$, indo muito além das competências mínimas traçadas em lei, mas sempre com o cuidado de não tomar partido no jogo político. E, não se deve negar, o suporte político reiteradamente conferido pelo Congresso e a solidez do estatuto legal do CBO decerto explicam parte do sucesso alcançado pela agência.

\section{A SITUAÇÃO DO BRASIL: CONSELHO DE GESTÃO FISCAL E INSTITUIÇÃO FISCAL INDEPENDENTE}

A ideia de uma IFI para o Brasil não é propriamente nova. Pode-se dizer que surgiu ainda no ano 2000, com o advento da Lei de Responsabilidade Fiscal (LRF). A referência óbvia, aqui, é ao Conselho de Gestão Fiscal (CGF), que seria responsável pelo "acompanhamento e a avaliação, de forma permanente, da política e da operacionalidade da gestão fiscal" (art. 67) ${ }^{65}$.

"Em teoria", diz Guilherme Bueno de Camargo, "o Conselho de Gestão Fiscal seria responsável pela guarda da LRF em sua dimensão prática"66. Um complemento ao trabalho já

${ }^{61}$ JOYCE, Philip, The Congressional Budget Office: honest numbers, power, and policymaking, cit., p. $154-206$.

${ }^{62}$ Cf. KRUGMAN, Paul. Trumpcare vs. Obamacare: Apocalypse Foretold. New York Times (on line), 13/03/17. Disponível em <https://www.nytimes.com/2017/03/13/opinion/trumpcare-vs-obamacare-apocalypse-foretold.html > (acesso em 24/10/2020). Vale ressaltar que o papel do CBO para a rejeição congressual à primeira proposta de Trump foi reverberada até mesmo pela mídia brasileira. Cf. FLECK, Isabel. Ante provável derrota, republicanos adiam votação do Trumpcare . Folha de São Paulo, 23/03/2017. Disponível em <http://www1.folha.uol.com.br/mundo/2017/03/1869126-ante-provavel-derrota-republicanos-adiam-votacao-dotrumpcare.shtml> (acesso em 24/10/2020)

${ }^{63}$ Além das matérias já citadas, cf. BERNSTEIN, Jared. A proposal to the incoming administration to lower the trade deficit. Washington Post, 28/11/2016. Disponível em <https://www.washingtonpost.com/posteverything/wp/2016/11/28/a-proposal-to-the-incoming-administration-tolower-the-trade-deficit/?utm_term=.6c5a24bd2a64> ou GREELEY, Brendan. How Republicans Plan to Spend Like Crazy Without Running Up Debt. Bloomberg, 17/11/2016. Disponível em < https://www.bloomberg.com/news/articles/2016-11-17/how-the-white-house-could-justify-a-debt-driven-keynesianstimulus> (acesso em 24/10/2020)

${ }^{64}$ Segundo Joyce, "it seems clear at this point in time that CBO does directly communicate with - if not serve - the public. It is, in that sense, less like the Congressional Research Service, much of whose work is not even publicly available, and more like the GAO which works hard to garner attention for its analyses." Cf. JOYCE, Philip. The Congressional Budget Office: honest numbers, power, and policymaking. Washington D.C.: Georgetown University Press, 2011, p. 299.

${ }^{65}$ BRASIL. Lei Complementar no 101, de 04 de maio de 2000. Brasília. DF. Diário Oficial da União de 05/05/2000.

66 CAMARGO, Guilherme Bueno. Governança Republicana e Orçamento: as Finanças Públicas a Serviço da Sociedade. In CONTI, J. Mauricio; SCAFF, Fernando F. (coords.). Orçamentos públicos e direito financeiro. São Paulo: Revista dos Tribunais, 2011, p. 777.

Revista de Direito Brasileira | Florianópolis, SC | v. 27 | n. 10 | p.70-91 | Set./Dez. 2020 
executado pelos Tribunais de Contas. Nesse contexto, o motivo para a criação do CGF no Brasil aproxima-se daquele que viria a ensejar, alguns anos depois, a propositura das novas IFIs como solução ao descumprimento das regras de responsabilidade fiscal na União Europeia, em meio ao cenário de crise pós- $2008^{67}$.

Como se infere da leitura do art. 67 da LRF, o papel atribuído ao CGF não é de natureza jurídico-formal, ou seja, de mera verificação do cumprimento de normas legais postas, tampouco busca a responsabilização financeira de sujeitos desviantes, como sói acontecer com os Tribunais de Contas. Trata-se, na verdade, de controle de efetividade, centrado nos aspectos qualitativos, prudenciais e pragmáticos da gestão fiscal em si, por meio de um arco de competências que envolve a coordenação e harmonização dos entes federativos (inciso I), a disseminação de boas práticas (inciso II), a edição de normas gerais contábeis (inciso III) e a produção de análises, estudos e diagnósticos (inciso IV).

Vê-se, portanto, que o cumprimento da missão atribuída ao CGF exigiria um esforço institucional amplo desse órgão, até porque o sucesso dos estatutos fiscais depende, entre outros fatores, de sua abrangência subjetiva e do compromisso político em torno de sua efetivação ${ }^{68}$. Daí a composição plural e representativa também anunciada no caput do art. 67 da LRF, que inclui "representantes de todos os Poderes e esferas de Governo, do Ministério Público e de entidades técnicas representativas da sociedade". Composição esta que poderia conferir maior legitimidade às ações do CGF, além de reduzir custos políticos do processo decisório e induzir a adesão de seus partícipes às práticas gestadas no Conselho.

No entanto, a lei federal ordinária que viabilizaria a operacionalização do CGF até hoje não editada ${ }^{69}$, muito provavelmente em virtude da composição plural estabelecida para o Conselho. Aparentemente, na visão de muitos, o grau de legitimidade possibilitado pela composição prevista no art. 67 da LRF não compensaria os custos impostos ao andamento da política fiscal, que poderia se tornar disfuncional e pouco dinâmica ${ }^{70}$, tendo em vista interesses divergentes dos membros. ${ }^{71}$ Enquanto não é regulamentado o CGF, algumas de suas competências são exercidas, em caráter provisório e com sucesso apenas relativo ${ }^{72}$, pela Secretaria do Tesouro Nacional (STN), na condição de órgão central de contabilidade da União, consoante o permissivo do art. $50, \S 2^{\circ}$, da $\mathrm{LRF}^{73}$.

\footnotetext{
${ }^{67}$ Segundo SILVA, Suzana Tavares da. A Intervenção de Organismos Independentes na Avaliação das Regras Fiscais e o Respectivo Contributo para a Sustentabilidade do Sistema Fiscal - o Conselho das Finanças Públicas. Revista Argumentum - RA, Marília/SP, v. 16, Jan.-Dez. 2015, p. 359.

${ }^{68}$ Cf. LIMA, Edilberto Carlos Pontes. Curso de Finanças Públicas: Uma Abordagem Contemporânea. São Paulo: Atlas, 2015, p.245.

${ }^{69}$ Trata-se de exigência do art. 67, § $2^{\circ}$, da LRF. Segundo AFONSO, José Roberto e RIBEIRO, Leonardo. Um Conselho para Responsabilidade Fiscal. Revista Conjuntura Econômica, Rio de Janeiro/RJ, v. 70, no 8, Ago. 2016, p. 21, há cerca de 10 projetos de lei em tramitação a respeito do Conselho de Gestão Fiscal. Sobre o tema, cf. também CONTI, José Mauricio. Levando o Direito Financeiro a Sério. $2^{\mathrm{a}}$ ed. São Paulo: Blucher, 2019, p. 263-267.

${ }^{70}$ As resistências dos agentes políticos são brevemente relatadas por AFONSO, José Roberto e RIBEIRO, Leonardo. Um Conselho para Responsabilidade Fiscal. Revista Conjuntura Econômica, Rio de Janeiro/RJ, v. 70, nº 8, Ago. 2016, p. $20 / 21$.

${ }^{71}$ Não por outro motivo, o Projeto de Lei do Senado no 141/2014, de autoria do Senador Paulo Bauer, já aprovado na Câmara Alta, busca retirar as amarras do art. 67, caput, da LRF, omitindo qualquer referência expressa aos membros do CGF. Após o encaminhamento à Câmara dos Deputados, o PLS no 141/2014 transformou-se em PLP n ${ }^{\circ}$ 210/2015, sendo anexado ao PLP 169/2019, de relatoria de José Serra, que trata da mesma matéria. Este último projeto pode ser obtido por meio do seguinte endereço: <https://www.camara.leg.br/proposicoesWeb/fichadetramitacao?idProposicao=2210108> (acesso em 24/10/2020).

72 "Relativo" porque a STN não teria sido capaz de efetivar sua produção normativa, tampouco de impedir as "maquiagens contábeis" ocorridas no âmbito da União. O diagnóstico, que parece amplamente aceito, é referendado por AFONSO, José Roberto e RIBEIRO, Leonardo. Um Conselho para Responsabilidade Fiscal. Revista Conjuntura Econômica, Rio de Janeiro/RJ, v. 70, nº 8, Ago. 2016, p. $20 / 22$.

${ }^{73}$ LRF. Art. 50, $\S 2^{\circ}$. A edição de normas gerais para consolidação das contas públicas caberá ao órgão central de contabilidade da União, enquanto não implantado o conselho de que trata o art. 67.
}

Revista de Direito Brasileira | Florianópolis, SC | v. 27 | n. 10 | p.70-91 | Set./Dez. 2020 
Mais recentemente, veio à tona a ideia, agora concretizada, de uma IFI constituída sob a forma de escritório parlamentar. Inicialmente, tentou-se a reforma da Constituição por meio da PEC $n^{\circ}$ 83/2015, de autoria do Senado Renan Calheiros, que pretendia inserir na Lei Magna o art. 166-A, a fim de dispor sobre a então denominada Autoridade Fiscal Independente. A proposta, contudo, não vingou. Tomou-se então um caminho alternativo com a edição de uma resolução interna do Senado para dispor sobre a matéria. Em $1^{\circ}$ de novembro de 2016, anunciou-se a aprovação da Resolução no 42/2016 ${ }^{74}$.

\subsection{A IFI BRASILEIRA À LUZ DA RESOLUÇÃO Nº 42/2016 DO SENADO}

De acordo com o art. $1^{\circ}$ da Resolução $n^{\circ} 42 / 2016$, a IFI teria as seguintes finalidades: divulgar suas estimativas de parâmetros e variáveis relevantes para a construção de cenários fiscais e orçamentários (inciso I); analisar a aderência do desempenho de indicadores fiscais e orçamentários às metas definidas na legislação pertinente (inciso II); mensurar o impacto de eventos fiscais relevantes, especialmente os decorrentes de decisões dos Poderes da República, incluindo os custos das políticas monetária, creditícia e cambial (inciso III); projetar a evolução de variáveis fiscais determinantes para o equilíbrio de longo prazo do setor público (inciso IV). Consta do art. $1^{\circ}, \S 1^{\circ}$, que essas competências "não excluem nem limitam aquelas atribuídas a órgãos jurisdicionais, normativos ou de controle". Cumpre destacar também a previsão do art. $1^{\circ}, \S 11$, segundo o qual os relatórios elaborados pela IFI para cumprimento das competências indicadas serão tornados públicos após aprovação pela maioria do Conselho Diretor.

De acordo com o art. $1^{\circ}$ da Resolução $n^{\circ} 42 / 2016$, a IFI brasileira deve ser liderada por Conselho Diretor composto de 3 (três) membros: 1 (um) diretor-executivo indicado pelo Presidente do Senado Federal (art. $\left.1^{\circ}, \S 2^{\circ}, I\right)$; (um) diretor indicado pela Comissão de Assuntos Econômicos (CAE) do Senado Federal ( $\operatorname{art} 1^{\circ}, \S 2^{\circ}$, II); 1 (um) diretor indicado pela Comissão de Transparência, Governança, Fiscalização e Controle e Defesa do Consumidor (CTFC) do Senado Federal (art. $1^{\circ}$, $\S 2^{\circ}$, III, com redação dada pela Resolução $n^{\circ} 3 / 2017$ ). Todos devem ser "brasileiros de reputação ilibada e detentores de notório saber nos temas de competência da Instituição Fiscal Independente", sendo submetidos a arguição pública e aprovação pelo Senado Federal ( $\operatorname{art.} 1^{\circ}, \S 3^{\circ}$ ). Aos membros do Conselho Diretor é proibido o exercício regular de outra atividade profissional, inclusive gestão operacional de empresa ou filiação político-partidária (art. $1^{\circ}, \S 8^{\circ}$ ).

A Resolução estabelece mandatos não coincidentes de 4 (quatro) anos para os membros do Conselho Diretor, a serem nomeados a cada 2 (dois) anos, alternadamente, não admitida recondução (art. $1^{\circ}, \S \S 4^{\circ}$ e $6^{\circ}$ ). Os mandatos iniciais, todavia, sujeitam-se a regra transitória diversa: mandato de 6 (seis) anos para o diretor-executivo, de 4 (quatro) para o diretor indicado pela CAE e de 2 (dois) para o diretor indicado pela CTFC. Os mandatos podem ser extintos por exoneração apenas "em caso de renúncia, condenação judicial transitada em julgado ou processo administrativo disciplinar, bem como por voto de censura aprovado pela maioria absoluta dos membros do Senado Federal" (art. $1^{\circ}, \S 7^{\circ}$ ).

A IFI conta também com um Conselho de Assessoramento Técnico, a ser integrado por até 5 (cinco) brasileiros de reputação ilibada e detentores de notório saber nos temas de competência da Instituição. A nomeação é feita pelo diretor-executivo e dá-se por tempo indeterminado, mas as reuniões do Conselho são preferencialmente mensais ${ }^{75}$. Os conselheiros não são remunerados, mas suas despesas $\mathrm{cm}$ transporte, hospedagem e alimentação serão custeadas nos termos do Ato da Comissão Diretora n 5 de 2006 e do Ato da Diretoria-Geral no 21 de 2014,

\footnotetext{
${ }^{74}$ BRASIL. SENADO FEDERAL. Resolução $n^{o} 42$, de $1^{o}$ de novembro de 2016. Brasília. DF. Diário Oficial da União de $03 / 11 / 2016$.

${ }^{75}$ Os atuais membros do Conselho foram designados pelo Ato do Presidente ${ }^{\circ} 8 / 2019$.
}

Revista de Direito Brasileira | Florianópolis, SC | v. 27 | n. 10 | p.70-91 | Set./Dez. 2020 
conforme o Ato da Comissão Diretora $n^{\circ} 10$ de $2016^{76}$. O estafe propriamente dito da IFI é providenciado mediante remanejamento de recursos humanos do próprio Senado, assegurando-se que pelo menos $60 \%$ de seus integrantes possuam grau de mestre ou doutor no objeto de atuação da IFI (art. $2^{\circ}$, caput). Os recursos orçamentários da IFI não serão objeto de contingenciamento (art. $2^{\circ}$, parágrafo único).

Por meio da Mesa do Senado, a IFI poderá encaminhar pedidos escritos de informação a Ministros de Estado e a outros titulares de órgãos diretamente subordinados à Presidência da República (art. $1^{\circ}, \S 10$ ) e, de acordo com o art. $3^{\circ}$ da Resolução, "as instituições oficiais competentes deverão prestar todas as informações necessárias ao pleno e adequado desempenho das atribuições da Instituição Fiscal Independente".

\subsection{ATUAÇÃO DA IFI BRASILEIRA ATÉ O PRESENTE MOMENTO}

Embora ainda jovem, a IFI brasileira vem demonstrando proatividade. Vale destacar que, desde fevereiro deste ano de 2017, a IFI tem publicado mensalmente o seu Relatório de Acompanhamento Fiscal (RAF), contendo os principais indicadores fiscais e econômicos, com enfoque prospectivo ${ }^{77}$. Além disso, a IFI já concluiu diversos estudos especiais, incluindo um trabalho sobre o nível adequado de reservas para o Brasil ${ }^{78}$. Como se não bastasse, a IFI já possui significativa presença na mídia brasileira, como revela, por exemplo, a cobertura jornalística sobre a reforma da previdência, que chegou a apontar dados apresentados pelo Diretor-Executivo da agência ${ }^{79}$.

\section{AFINAL, O QUE PODEMOS APRENDER COM A EXPERIÊNCIA ESTRANGEIRA?}

O que a experiência estrangeira e os autores dedicados ao tema nos mostram é que a IFI, estritamente falando, não é necessária ou imprescindível à gestão fiscal. Ou seja, a IFI não pode ser encarada como a solução para todos os males, a bala de prata que matará o vampiro das contas públicas. Naturalmente, não se trata disso.

Como bem salienta Philip Joyce, "analistas e agências desenhadas para prover análises neutras podem fazer pouco para assegurar que a seus produtos seja dado o devido peso. Muitas vezes, essa análise assume importância demasiada. Outras vezes, é ignorada" ${ }^{80}$. Alice Rivlin, ela própria uma respeitada ex-líder do $\mathrm{CBO}$, afirma que "os Estados Unidos são um exemplo claro do triste fato de que ter uma instituição fiscal independente encarregada de lançar estimativas e relatórios objetivos não garante que os políticos agirão responsavelmente"81. Ao fim e ao cabo, de nada servem regras e instituições se os políticos responsáveis pela condução das finanças públicas não cumprirem suas obrigações legais. A IFI não pode (e nem deve) substituí-los.

\footnotetext{
${ }^{76}$ BRASIL. SENADO FEDERAL. Ato da Comissão Diretora $n^{o} 10$ de 2016. Brasília. DF. Boletim Administrativo do Senado Federal de 10/11/2016. Inteiro teor disponível em <https://adm.senado.gov.br/normas/ui/pub/normaConsultada;jsessionid=71A36D5342D0FEBAF377AF6507249998 ?0\&idNorma $=13834153>$ (acesso em 24/10/2020)

77 Cf. <https://www12.senado.leg.br/ifi/relatorio-de-acompanhamento-fiscal> (acesso em 24/10/2020)

78 PELLEGRINI, Josué Alfredo. Reservas Internacionais do Brasil: evolução, nível adequado e custo de carregamento. Brasília. Senado: Instituição Fiscal Independente, n. 1, mar/2017. Disponível em < http://www2.senado.leg.br/bdsf/bitstream/handle/id/529487/EE_Reservas_Internacionais.pdf?sequence=1> (acesso em 24/10/2020).

${ }^{79}$ A título ilustrativo, cf. PESSOA, Samuel. É preciso se informar para ser contra reforma da Previdência. Folha de São Paulo, 30/04/2017. Disponível em <http://www1.folha.uol.com.br/colunas/samuelpessoa/2017/04/1879849-epreciso-se-informar-para-ser-contra-reforma-da-previdencia.shtml $>$ (acesso em 24/10/20)

${ }^{80}$ JOYCE, Philip. The Congressional Budget Office: honest numbers, power, and policymaking. Washington D.C.: Georgetown University Press, 2011, p. 05.

${ }^{81}$ RIVLIN, Alice. Politics and Independent Analysis. In: KOPITS, George (Ed.). Restoring public debt sustainability: the role of independent fiscal institutions. Oxford: Oxford University Press, 2013, p. 21.
}

Revista de Direito Brasileira | Florianópolis, SC | v. 27 | n. 10 | p.70-91 | Set./Dez. 2020 
Como se não bastasse tal constatação, a literatura especializada é tímida ao mensurar os resultados atingidos pelas IFIs ao redor do mundo. Para George Kopits, "com relação à efetividade das IFIs, a resposta é confusa e difícil de documentar". Isso porque, segundo o estudioso, " muita da influência sobre o Executivo ou o Legislativo ocorre por meio de persuasão sutil, porém efetiva, no patamar do serviço público, abaixo do alcance do radar"82. Também Suzana Tavares, ao comentar o caso lusitano, celebra a contribuição da IFI para "o aumento da literacia financeira no país", mas não se arrisca a oferecer um diagnóstico mais ousado sobre a atuação do CFP, ressaltando "não ter o impacto na comunicação social que se esperaria e desejaria, pois poucas têm sido as referências à sua actividade nos principais serviços noticiosos, públicos e privados" ${ }^{13}$.

Apesar dessas ressalvas, boa parte das experiências internacionais também nos mostra que a IFI pode sim fortalecer a governança orçamentária e aperfeiçoar a gestão fiscal, desde que bem formatada institucionalmente, adequada para o enfrentamento dos problemas locais e gerida por líderes tecnicamente capazes e politicamente hábeis. Estes os maiores desafios à recém implantada IFI brasileira.

Quanto ao aspecto gerencial, pode-se falar, por ora, que a IFI brasileira tem sido gerida de maneira bastante adequada, principalmente à luz da trajetória do CBO americano, paradigma para as demais IFIs. A mais importante lição diz respeito à necessidade de que a IFI não enverede por querelas políticas e busque manter uma atuação profissional e isenta de partidarismos, a fim de manter sua credibilidade, que advém preponderantemente de sua excelência técnica. Por outro lado, no entanto, não deve a IFI apequenar-se a ponto de se confundir com um simples departamento de assessoria técnica. Assim, urge que seja proativa e construa sua própria agenda, com independência técnica e coragem para enfrentar os grandes temas da pauta vigente, ainda que possa desagradar peças importantes do jogo político. Por esse prisma, até aqui, a atuação da IFI tem sido bastante positiva.

Obviamente, decisões gerenciais são moldadas, sobretudo, por fatores institucionais. O grau de ousadia gerencial da IFI brasileira será diretamente proporcional ao suporte institucional que tiver. Aqui verificamos as principais fragilidades do modelo brasileiro.

Em primeiro lugar, o instrumento normativo que dá respaldo à criação da IFI, uma resolução do Senado, não é exatamente dos mais robustos. Como visto, a OCDE prescreve que a IFI resulte de amplo consenso no cenário político nacional (Princípio 1.1.) e que suas competências sejam dispostas em legislação superior (Princípio 3.1). É natural que assim seja, pois um estatuto mais forte não só revela forte apoio político à IFI como também ampara sua independência e dificulta sua extinção abrupta por razões mesquinhas. Não por outro motivo, o CBO norteamericano foi criado por lei formal sancionada pelo então Presidente da República, assim como quase todas as demais IFIs relevantes. No caso brasileiro, um agravante sob o viés político é o fato de que o então Presidente do Senado tentou implementar a IFI por meio de emenda constitucional, mas não conseguiu apoio suficiente para sua empreitada ${ }^{84}$.

No caso do Brasil, o emprego de resolução do Senado para a criação da IFI também é questionável sob o prisma estritamente jurídico.

Inicialmente, a Resolução que cria a IFI não cuida de matéria interna corporis, tampouco se ajusta ao rol constitucional de competências privativas do Senado (art. 52). Convém notar ainda que mecanismos de freios e contrapesos despidos de respaldo constitucional expresso padecem de imediata suspeição à luz do princípio da separação de poderes $\left(\operatorname{art} .2^{\circ}\right)$.

\footnotetext{
${ }^{82}$ KOPITS, George. Introduction and overview. In: KOPITS, George (Ed.). Restoring public debt sustainability: the role of independent fiscal institutions. Oxford: Oxford University Press, 2013, p. 11.

${ }^{83}$ SILVA, Suzana Tavares da. A Intervenção de Organismos Independentes na Avaliação das Regras Fiscais e o Respectivo Contributo para a Sustentabilidade do Sistema Fiscal - o Conselho das Finanças Públicas. Revista Argumentum - RA, Marília/SP, v. 16, Jan.-Dez. 2015, p. 373/374.

${ }_{84}$ Trata-se da PEC $\mathrm{n}^{\circ}$ 83/2015, cuja tramitação pode ser consultada em <https://www25.senado.leg.br/web/atividade/materias/-/materia/121994> (acesso em 24/10/2020)
}

Revista de Direito Brasileira | Florianópolis, SC | v. 27 | n. 10 | p.70-91 | Set./Dez. 2020 
Outro ponto crítico diz respeito ao encaixe da IFI no modelo de controle externo adotado pela Constituição, que atribui essa tarefa ao Congresso Nacional, com o auxílio do Tribunal de Contas da União ${ }^{85}$. Admitindo-se a possibilidade de criação da IFI por ato meramente parlamentar, teria o Senado competência para fazê-lo sozinho, sem o concurso da Câmara dos Deputados, que também compõe o Congresso Nacional? Ademais, não seria o Tribunal de Contas o único agente constitucionalmente habilitado para o exercício auxiliar da fiscalização financeira e orçamentária sob o prisma do controle externo? Questões como essas podem minar a credibilidade institucional da IFI brasileira, ainda que não atinjam sua reputação técnica. A seu favor, pode-se argumentar que a IFI se assemelha muito mais a um think tank, ou seja, uma espécie de centro de pesquisa. Não se trataria, portanto, de uma agência de controle típica.

Não custa rememorar também o papel atribuído pela Lei Complementar no 101/2000 ao Conselho de Gestão Fiscal (CGF). Não seria o CGF a versão brasileira mais genuína e legítima da IFI? Há quem conteste a sugestão com o argumento de que a CGF não seria propriamente uma IFI, mas sim um órgão de cooperação intergovernamental inspirado na Advisory Commission on Intergovernmental Relations (Acir), agência americana extinta em $1996^{86}$. No entanto, a Acir não possuía competências no campo da contabilidade pública e das regras fiscais, ocupando-se predominantemente da operacionalização dos programas de transferências intergovernamentais oriundas do governo federal (federal grants) e de questões tributárias sensíveis para as relações interfederativas $^{87}$. Neste último aspecto, a Acir norte-americana estaria muito mais próxima do Confaz brasileiro ${ }^{88}$. De resto, deve-se lembrar que a ideia da IFI não é necessariamente incompatível com o equacionamento de problemas federativos. Basta mencionar o exemplo da IFI belga, que tem atribuições intergovernamentais ${ }^{89}$. Ao próprio $\mathrm{CBO}$, aliás, é dado opinar sobre assuntos subnacionais eventualmente [Budget Act, Sec. 202 (2) (a) $\left.{ }^{90}\right]$.

Há outras controvérsias sobre dispositivos juridicamente sensíveis ou de difícil operacionalização material. Veja-se, por exemplo, a vedação de contingenciamento dos recursos

${ }^{85}$ CONTI, José Mauricio. Levando o direito financeiro a sério: a luta continua. $3^{\mathrm{a}}$ ed. Sâo Paulo: Blucher, 2019 , p. 317-321.

${ }^{86}$ AFONSO, José Roberto e RIBEIRO, Leonardo. Um Conselho para Responsabilidade Fiscal. Revista Conjuntura Econômica, Rio de Janeiro/RJ, v. 70, nº 8, Ago. 2016, p. 20/22.

${ }^{87}$ ESTADOS UNIDOS. Advisory Commission on Intergovernmental Relations (Acir) Act. Public Law 86-380, Sept. 24, 1959. Conforme o Estatuto da Acir, suas competências seriam as seguintes (tradução livre): (1) reunir representantes dos governos federal, estaduais e locais para a consideração de problemas comuns; (2) proporcionar um fórum para discutir a administração e a coordenação de transferências federais e outros programas que requeiram cooperação intergovernamental; (3) oferecer atenção crítica às condições e controles envolvidos na administração dos programas de transferências federais; (4) providenciar assistência técnica aos poderes Executivo e Legislativo do Governo Federal na revisão de projetos de lei para determinar seu efeito geral no sistema federal; (5) encorajar debate e estudo de problemas públicos emergentes, ainda em seu estado inicial, que possam demandar cooperação intergovernamental; (6) recomendar, nos limites da Constituição, a mais desejável alocação de funções governamentais, responsabilidades e receitas entre os diversos níveis de governo; e (7) recomendar métodos de coordenação e simplificação de leis tributárias e práticas administrativas para alcançar uma relação fiscal mais ordenada e menos competitiva entre os níveis de governo e para reduzir o ônus da obediência para os contribuintes. $\mathrm{O}$ teor do Estatuto da Acir foi obtido em <https://www.gpo.gov/fdsys/pkg/STATUTE-73/pdf/STATUTE-73-Pg703.pdf> (acesso em 24/10/2020)

${ }^{88}$ Além de ser responsável por promover a celebração de convênios, para efeito de concessão ou revogação de isenções, incentivos e benefícios fiscais do ICMS, nos termos do art. $155, \S 2^{\circ}$, inciso XII, alínea "g", da Constituição, o Confaz também gerencia dados relevantes para a condução da política econômico-fiscal e para o aperfeiçoamento da administração tributária de seus partícipes, além de promover estudos sobre o sistema tributário nacional, especialmente quanto à relação entre União e Estados. O descritivo das competências do Confaz pode ser encontrado em seu sítio: <https://www.confaz.fazenda.gov.br/menu-de-apoio/competencias> (acesso em 24/10/2020)

${ }^{89}$ VON TRAPP, Lisa; LIENERT, Ian; WEHNER, Joachim. Principles for independent fiscal institutions and case studies. OECD Journal on Budgeting, v. 15, n. 2, 2016, p. 65/76.

${ }^{90}$ Budget Act. Sec. 202(2) At the request of any committee of the Senate or the House of Representatives, the Office shall, to the extent practicable, consult with and assist such committee in analyzing the budgetary or financial impact of any proposed legislation that may have- (A) a significant budgetary impact on State, local, or tribal governments.

Revista de Direito Brasileira | Florianópolis, SC | v. 27 | n. 10 | p.70-91 | Set./Dez. 2020 
atribuídos à IFI (art. 2º parágrafo único, da Resolução nº 42/2016). Qual é a efetividade real de tal regra? De mais a mais, o art. 163 da Constituição reserva à lei complementar o domínio das finanças públicas e, com base nesse dispositivo constitucional, o art. $9^{\circ}$ da Lei de Responsabilidade Fiscal dispõe sobre as hipóteses de contingenciamento. Poderia a Resolução do Senado inovar em tal matéria, vedando o contingenciamento sem qualquer consideração sobre a natureza da despesa, se obrigatória ou discricionária? Não teria também ingressado em domínio próprio da lei de diretrizes orçamentárias, a quem caberia listar outras despesas não contingenciáveis (art. $9^{\circ}, \S 2^{\circ}, \mathrm{LRF}$ )?

Outra regra frágil é a constante do art. $3^{\circ}$ da Resolução n 42/2016, segundo o qual "as instituições oficiais competentes deverão prestar todas as informações necessárias ao pleno e adequado desempenho das atribuições da Instituição Fiscal Independente." Pois bem: estaria um órgão do Poder Executivo obrigado a fornecer dados de interesse da IFI por força da Resolução? O contraste com a solução legal norte-americana não poderia ser mais evidente.

Além do mais, não há uma integração clara da IFI ao processo decisório físcal, prejudicando sua contribuição efetiva para as decisões do Parlamento. Note-se, por exemplo, que a competência para mensurar o impacto de eventos fiscais relevantes não possui qualquer conexão com o sistema PAYGO previsto na LRF, ao contrário do que ocorre nos EUA, como visto.

\section{CONCLUSÃO}

Diante da discussão desenvolvida na seção anterior, concluímos que a iniciativa do Senado tem grandes méritos. No entanto, a forma de implementação da IFI brasileira, permeada por fragilidades jurídicas e institucionais, pode impedir a instituição de alcançar resultados mais significativos ao longo de sua trajetória, caso venha a enfrentar a oposição de outros atores relevantes da arena institucional. Resta saber se a gestão da IFI brasileira, até aqui exemplar, conseguirá neutralizar os riscos apontados e promover as reformas necessárias para o seu adequado desenvolvimento.

\section{REFERÊNCIAS}

AFONSO, José Roberto e RIBEIRO, Leonardo. Um Conselho para Responsabilidade Fiscal. Revista Conjuntura Econômica, Rio de Janeiro/RJ, v. 70, nº 8, Ago. 2016, p. 20-22.

BERNSTEIN, Jared. A proposal to the incoming administration to lower the trade deficit. Washington Post, 28/11/2016. Disponível em <https://www.washingtonpost.com/posteverything/wp/2016/11/28/a-proposal-to-the-incomingadministration-to-lower-the-trade-deficit/?utm_term=.6c5a24bd2a64>

BIJOS, Paulo. Instituições Fiscais Independentes: Subsídios para a Implantação de um Imperativo Fiscal no País. Senado Federal: Orçamento em Discussão, Brasília/DF, n. 15, 2015, p. 6-26.

BRASIL. Lei Complementar $n^{o}$ 101, de 04 de maio de 2000. Brasília. DF. Diário Oficial da União de 05/05/2000.

BRASIL. SENADO FEDERAL. Resolução $n^{\circ} 42$, de $1^{o}$ de novembro de 2016. Brasília. DF. Diário Oficial da União de 03/11/2016. 
BRASIL. SENADO FEDERAL. Ato da Comissão Diretora $n^{o} 10$ de 2016. Brasília. DF. Boletim Administrativo do Senado Federal de 10/11/2016. Inteiro teor disponível em <https://adm.senado.gov.br/normas/ui/pub/normaConsultada;jsessionid=71A36D5342D0FEBAF 377AF6507249998?0\&idNorma=13834153> (acesso em 24/10/2020)

BUDD, Alan. Preface. In: KOPITS, George (Ed.). Restoring public debt sustainability: the role of independent fiscal institutions. Oxford: Oxford University Press, 2013.

CAMARGO, Guilherme Bueno. Governança Republicana e Orçamento: as Finanças Públicas a Serviço da Sociedade. In CONTI, J. Mauricio; SCAFF, Fernando F. (coords.). Orçamentos públicos e direito financeiro. São Paulo: Revista dos Tribunais, 2011, p. 769-784.

CHOHAN, Osman W. Canada and the global network of parliamentary budget officers. Canadian parliamentary review, v. 36, n. 3, 2013, p. 17-20.

CONTI, José Mauricio. Levando o direito financeiro a sério: a luta continua. $3^{\mathrm{a}}$ ed. São Paulo: Blucher, 2019.

DAUSTER, William. The Congressional Budget Process. In: GARRETT, Elizabeth; GRADDY, Elizabeth and JACKSON, Howell. Fiscal Challenges: an interdisciplinary approach to budget policy. Cambridge: Cambridge University Press, 2008, p. 4-35.

DEBRUN, Xavier; HAUNER, David; KUMAR, Manmohan S. Independent fiscal agencies. Journal of Economic Surveys, v. 23, n. 1, 2009, p. 44-81.

DEBRUN, Xavier; TAKAHASHI, Keiko. Independent Fiscal Councils in Continental Europe: Old Wine in New Bottles?. DICE Report, v. 9, n. 3, 2011, p. 44-49.

EICHENGREEN, Barry; HAUSMANN, Ricardo; VON HAGEN, Jürgen. Reforming budgetary institutions in Latin America: the case for a national fiscal council. In: PICCIOTTO, Robert; WIESNER, Eduardo. Evaluation and development: the institutional dimension. World Bank: World Bank series on evaluation and development, 1998, p. 155-177.

ESTADOS UNIDOS. Advisory Commission on Intergovernmental Relations (Acir) Act. Public Law 86-380, Sept. 24, 1959.

ESTADOS UNIDOS. CONGRESSO. U. S. Congressional Budget and Impoundment Control Act of 1974. Public Law, n. 93-344, July 12, 1974. Texto atualizado disponível em <https://www.govinfo.gov/content/pkg/COMPS-10356/pdf/COMPS-10356.pdf> (acesso em 24/10/2020)

ESTADOS UNIDOS. Congressional Budget Office. Organization and Staffing [website]. Disponível em < https://www.cbo.gov/about/organization-and-staffing> (acesso em 24/10/2020)

FLECK, Isabel. Ante provável derrota, republicanos adiam votação do Trumpcare . Folha de São Paulo, 23/03/2017. Disponível em <http://www1.folha.uol.com.br/mundo/2017/03/1869126-anteprovavel-derrota-republicanos-adiam-votacao-do-trumpcare.shtml> (acesso em 24/10/2020)

FUNDO MONETÁRIO INTERNACIONAL. The Functions and Impact of Fiscal Councils, 2013, p 1-62. 
GREELEY, Brendan. How Republicans Plan to Spend Like Crazy Without Running Up Debt. Bloomberg, 17/11/2016. Disponível em <https://www.bloomberg.com/news/articles/2016-1117/how-the-white-house-could-justify-a-debt-driven-keynesian-stimulus > (acesso em 24/10/2020)

JOYCE, Philip. The Congressional Budget Office: honest numbers, power, and policymaking. Washington D.C.: Georgetown University Press, 2011.

JOYCE, Philip. The Congressional Budget Office at Middle Age. Hutchins Center Working Papers, 9, 2015, p. 1-30.

JOYCE, Philip G.; REISCHAUER, Robert D. Deficit Budgeting: The Federal Budget Process and Budget Reform. Harvard Journal on Legislation, v. 29, 1992, p. 429-453.

KOPITS, George. Introduction and overview. In: KOPITS, George (Ed.). Restoring public debt sustainability: the role of independent fiscal institutions. Oxford: Oxford University Press, 2013, p. 1-15.

KOPITS, George; ROMHÁNYI, Balázs. Hungary: A Short-Lived Fiscal Watchdog. In: KOPITS, George (Ed.). Restoring public debt sustainability: the role of independent fiscal institutions. Oxford: Oxford University Press, 2013, p. 212-233.

KRUGMAN, Paul. Trumpcare vs. Obamacare: Apocalypse Foretold. New York Times (on line), 13/03/17. Disponível em <https:/www.nytimes.com/2017/03/13/opinion/trumpcare-vsobamacare-apocalypse-foretold.html > (acesso em 24/10/2020).

LIMA, Edilberto Carlos Pontes. Curso de Finanças Públicas: Uma Abordagem Contemporânea. São Paulo: Atlas, 2015.

MENDONÇA, Eduardo Furtado Bastos de. A constitucionalização das finanças públicas no Brasil: devido processo orçamentário e democracia. Rio de Janeiro: Renovar, 2010.

OCDE - Organização para Cooperação e Desenvolvimento Econômico. Recommendation of the Council on Principles for Independent Fiscal Institutions. OECD Network of Parliamentary Budget Officials and Independent Fiscal Institutions, 2014.

OLIVEIRA, Weder de. Curso de Responsabilidade Fiscal. $2^{\mathrm{a}}$ ed. Belo Horizonte: Fórum, 2015.

PELLEGRINI, Josué Alfredo. Reservas Internacionais do Brasil: evolução, nível adequado e custo de carregamento. Brasília. Senado: Instituição Fiscal Independente, n. 1, mar/2017.

Disponível em

<http://www2.senado.leg.br/bdsf/bitstream/handle/id/529487/EE_Reservas_Internacionais.pdf?se quence $=1>($ acesso em 24/10/2020)

PESSOA, Samuel. É preciso se informar para ser contra reforma da Previdência. Folha de São Paulo, 30/04/2017. Disponível em <http://www1.folha.uol.com.br/colunas/samuelpessoa/2017/04/1879849-e-preciso-se-informarpara-ser-contra-reforma-da-previdencia.shtml> ( acesso em 24/10/2020) 
PRADO, Mariana; TREBILCOCK, Michael. Path dependence, development, and the dynamics of institutional reform. University of Toronto Law Journal, v. 59, n. 3, 2009, p. 341/379.

RIVLIN, Alice. Politics and Independent Analysis. In: KOPITS, George (Ed.). Restoring public debt sustainability: the role of independent fiscal institutions. Oxford: Oxford University Press, 2013, p 19-31.

RODRIGUES, Diogo Luiz Cordeiro. Orçamento Público no Canadá: a emergência da Instituição Fiscal Independente. Rio de Janeiro: Lumen Juris, 2016.

SILVA, Suzana Tavares da. A Intervenção de Organismos Independentes na Avaliação das Regras Fiscais e o Respectivo Contributo para a Sustentabilidade do Sistema Fiscal - o Conselho -das Finanças Públicas. Revista Argumentum - RA, Marília/SP, v. 16, Jan.-Dez. 2015, p. 357-377.

STEUERLE, Eugene and RENNANE, Stephanie. United States: Pioneer in Fiscal Surveillance. In: KOPITS, George (Ed.). Restoring public debt sustainability: the role of independent fiscal institutions. Oxford: Oxford University Press, 2013, p. 99-120.

STEWART, Miranda. The Australian Parliamentary Budget Office: A sustainable innovation in fiscal decision-making?. University of Melbourne Legal Studies Research Paper, n. 628, 2013, p. $1-31$.

VON TRAPP, Lisa; LIENERT, Ian; WEHNER, Joachim. Principles for independent fiscal institutions and case studies. OECD Journal on Budgeting, v. 15, n. 2, 2016, p. 9-272.

WEHNER, Joachim. Assessing the power of the purse: An index of legislative budget institutions. Political studies, v. 54, n. 4, 2006, p. 767-785. 